\title{
Nano-Curcumin Prevents Cardiac Injury, Oxidative Stress and Inflammation, and Modulates TLR4/NF-KB and MAPK Signaling in Copper Sulfate-Intoxicated Rats
}

\author{
Wedad S. Sarawi ${ }^{1}{ }^{(}$, Ahlam M. Alhusaini ${ }^{1}{ }^{(}$, Laila M. Fadda $^{1}$, Hatun A. Alomar ${ }^{1}$, Awatif B. Albaker ${ }^{1}$, \\ Amjad S. Aljrboa ${ }^{1}$, Areej M. Alotaibi ${ }^{1,2}$, Iman H. Hasan ${ }^{1}$ and Ayman M. Mahmoud ${ }^{3, * \mathbb{D}}$ \\ 1 Pharmacology and Toxicology Department, Faculty of Pharmacy, King Saud University, Riyadh 11451, \\ Saudi Arabia; wsarawi@ksu.edu.sa (W.S.S.); aelhusaini@ksu.edu.sa (A.M.A.); lfadda@ksu.edu.sa (L.M.F.); \\ hetalomar@ksu.edu.sa (H.A.A.); abaker@ksu.edu.sa (A.B.A.); 441203053@student.ksu.edu.sa (A.S.A.); \\ 442204129@student.ksu.edu.sa (A.M.A.); ihasan@ksu.edu.sa (I.H.H.) \\ 2 Department of Pharmacology and Toxicology, College of Pharmacy, Umm Al-Qura University, \\ Makkah 21955, Saudi Arabia \\ 3 Physiology Division, Zoology Department, Faculty of Science, Beni-Suef University, Beni-Suef 62514, Egypt \\ * Correspondence: ayman.mahmoud@science.bsu.edu.eg
}

Citation: Sarawi, W.S.; Alhusaini, A.M.; Fadda, L.M.; Alomar, H.A.; Albaker, A.B.; Aljrboa, A.S.; Alotaibi, A.M.; Hasan, I.H.; Mahmoud, A.M. Nano-Curcumin Prevents Cardiac Injury, Oxidative Stress and Inflammation, and Modulates TLR4/NF- $K B$ and MAPK Signaling in Copper Sulfate-Intoxicated Rats. Antioxidants 2021, 10, 1414. https:// doi.org/10.3390/antiox10091414

Academic Editor: Evangelos Zoidis

Received: 17 August 2021

Accepted: 1 September 2021

Published: 3 September 2021

Publisher's Note: MDPI stays neutral with regard to jurisdictional claims in published maps and institutional affiliations.

Copyright: (c) 2021 by the authors. Licensee MDPI, Basel, Switzerland. This article is an open access article distributed under the terms and conditions of the Creative Commons Attribution (CC BY) license (https:/ / creativecommons.org/licenses/by/ $4.0 /)$.
Abstract: Copper $(\mathrm{Cu})$ is essential for a plethora of biological processes; however, its high redox reactivity renders it potentially toxic. This study investigated the protective effect of curcumin (CUR) and nano-CUR (N-CUR) against Cu cardiotoxicity, emphasizing the role of oxidative stress, TLR4/NF$\mathrm{KB}$ and mitogen-activated protein kinase (MAPK) signaling and cell death in rats. Rats received $100 \mathrm{mg} / \mathrm{kg}$ copper sulfate $\left(\mathrm{CuSO}_{4}\right)$, a pesticide used for repelling pests, and were concurrently treated with CUR or N-CUR for 7 days. Cu caused cardiac injury manifested by elevated serum cardiac troponin I (cTnI), creatine kinase (CK)-MB, and lactate dehydrogenase (LDH), as well as histopathological alterations. Cardiac malondialdehyde (MDA), NF- $\mathrm{BB}$ p65, TNF- $\alpha$, and IL-6 were increased, and reduced glutathione (GSH), superoxide dismutase (SOD) and catalase were decreased in Cu-treated rats. CUR and N-CUR prevented cardiac tissue injury, decreased serum cTnI, CK-MB, and LDH, and cardiac MDA, NF- $\mathrm{B}$ p 65 , TNF- $\alpha$, and IL-6, and enhanced cellular antioxidants. CUR and N-CUR downregulated TLR4 and AP-1, and decreased the phosphorylation levels of p38 MAPK, JNK, and ERK1/2. In addition, CUR and N-CUR increased cardiac Bcl-2 and BAG-1, decreased Bax and caspase-3, and prevented DNA fragmentation. In conclusion, N-CUR prevents Cu cardiotoxicity by attenuating oxidative injury, inflammatory response, and apoptosis, and modulating TLR4/NF- $\mathrm{B}$ and MAPK signaling. The cardioprotective effect of N-CUR was more potent than the native form.

Keywords: curcumin nanoparticles; TLR4; inflammation; cardiotoxicity; DNA damage; oxidative stress

\section{Introduction}

Copper $(\mathrm{Cu})$ is an essential redox-active trace element found in many tissues. $\mathrm{Cu}$ is necessary for the proper functioning of a plethora of biological processes, including blood clotting, antioxidative defense, synthesis of neurotransmitters, protein homeostasis, energy production, and cellular metabolism [1,2]. $\mathrm{Cu}$ homeostasis is maintained by regulating its absorption, excretion, and circulating levels through precise regulatory mechanisms [3]. $\mathrm{Cu}$ has been established as an environmental pollutant that can harm humans and animals and has been detected in different tissues of aquatic animals $[4,5]$. The systemic absorption of $\mathrm{Cu}$ occurs through different routes, including the gastrointestinal tract, lungs, and skin [6]. Despite its pivotal roles, $\mathrm{Cu}$ becomes harmful when the normal limit is surpassed, and chronic exposure has been associated with neurodegenerative disorders, including Alzheimer's and Parkinson's diseases [7,8]. In addition, multiorgan dysfunction, such as liver, kidney, and neurological injuries, which could be fatal, are caused by 
$\mathrm{Cu}$ intoxication $[9,10]$. The liver is the major target for $\mathrm{Cu}$ toxicity, and hepatotoxicity is usually seen in individuals with Wilson disease and cirrhosis syndromes [9]. Kidney injury, arrhythmia, seizures, rhabdomyolysis, and intravascular hemolysis are among the clinical manifestations of $\mathrm{Cu}$ toxicity [11]. Accordingly, exposure to copper sulfate $\left(\mathrm{CuSO}_{4}\right)$ caused liver and kidney impairment and injury, and hepatic and renal $\mathrm{Cu}$ levels were increased in rats [12]. As with other metals, Cu toxicity is managed by chelating agents such as D-penicillamine, tetrathiomolybdate, trientine, and deferoxamine (DFO) [13]. However, the limited or moderate effectiveness and the adverse effects of these chelating agents necessitates the use of safer alternatives.

Cardiotoxicity is myocardial dysfunction and/or damage that could be induced by several drugs and chemicals, including $\mathrm{Cu}[5,14,15]$. Cu caused cardiotoxicity manifested by cellular stress, necrosis, and absence of heartbeat in zebrafish $[5,16]$. Studies have demonstrated an association between the exposure to high $\mathrm{Cu}$ concentrations and the increase in cardiovascular risk and heart failure incidence in humans [17-19]. Although the mechanisms underlying $\mathrm{Cu}$ toxicity are not fully understood, excess reactive oxygen species (ROS), oxidative stress [20,21], and endocrine perturbation [22] have been implicated. ROS are versatile oxidants that damage several cellular macromolecules, including lipids, proteins, and DNA, resulting in cell death [23,24]. Oxidative stress has been demonstrated in the hippocampus and frontal cortex of rats that received $\mathrm{CuSO}_{4}$ [25]. Impairment of memory and learning was associated with oxidative stress in the hippocampus of rats treated with $\mathrm{Cu}$ chloride [10]. These studies demonstrated the significant role of oxidative stress in $\mathrm{Cu}$ toxicity. Hence, suppression of oxidative stress can protect against cardiotoxicity and other deleterious effects of $\mathrm{Cu}$.

Curcumin (CUR) is a hydrophobic polyphenol found in turmeric [26] and possesses potent antioxidant [27], anti-inflammatory [28,29], and cardioprotective effects [30]. In a rat model of lung injury, CUR suppressed inflammation, oxidative stress, and apoptosis and enhanced antioxidant defenses [28]. The anti-inflammatory and antioxidant properties of CUR were demonstrated in a rat model of lipopolysaccharide (LPS)/diclofenac-induced liver injury [29]. CUR attenuated oxidative stress and inflammatory response and prevented tissue injury in experimental models of hepatotoxicity and nephrotoxicity induced by lead [31] and gentamicin [32,33]. In addition to boosting antioxidants, the therapeutic effect of CUR was associated with modulating toll-like receptor (TLR)-4/nuclear factorkappaB (NF-kB) and mitogen-activated protein kinase (MAPK) signaling in rat liver [29]. TLRs are members of the interleukin (IL)-1 receptor family, and TLR4 is expressed in the heart. These receptors enable cardiomyocytes to respond to endogenous or exogenous signals. Oxidative stress is one of the endogenous signals that activate TLRs and contribute to congestive heart failure (HF) [34]. Upon activation, TLR4 triggers the release of pro-inflammatory mediators through promoting NF- $\mathrm{kB}$ and MAPKs [35]. TLR4 is activated in several cardiac alterations, such as cardiotoxicity, cardiomyopathy, and HF [36]. However, the possible involvement of TLR4 signaling in Cu cardiotoxicity has not been demonstrated. This study investigated the effect of $\mathrm{Cu}$ exposure on cardiac TLR4/NF-kB and MAPK signaling in rats, and the possible protective role of CUR. Owing to the poor systemic bioavailability and rapid metabolism of CUR, the main drawbacks limiting its therapeutic uses [37], we aimed to investigate the protective effect of nano-CUR (N-CUR).

\section{Materials and Methods}

\subsection{Chemicals and Reagents}

N-CUR was obtained from Lipolife (Essex, UK) and DFO was supplied by Novartis Pharma AG (Rotkreuz, Switzerland). $\mathrm{CuSO}_{4}, \mathrm{CUR}$, primers, carboxymethylcellulose $(\mathrm{CMC})$, sodium dodecyl sulfate (SDS), agarose, pyrogallol, thiobarbituric acid (TBA), and reduced glutathione (GSH) were obtained from Sigma (St. Louis, MO, USA). Caspase-3 assay kit, NF- $\mathrm{kB}$ p65, cardiac troponin I (cTnI), Bax and Bcl-2 ELISA kits were supplied by MyBiosource (San Diego, CA, USA), and TNF- $\alpha$ and IL-6 ELISA kits were supplied by R\&D Systems (Minneapolis, MN, USA). Creatine kinase (CK)-MB and lactate dehydrogenase 
(LDH) kits were purchased from Spinreact (Girona, Spain). Antibodies against TLR4, $p$-p38 MAPK, p38 MAPK, pJNK, JNK, pERK1/2, ERK1/2, and $\beta$-actin were supplied by Novus Biologicals (Centennial, CO, USA). Other chemicals and kits were supplied by standard manufacturers.

\subsection{Animals and Treatments}

Male Wistar rats (180-200 g), obtained from the Animals Care Centre at King Saud University, were housed under standard conditions and $12 \mathrm{~h}$ light/dark cycle and given free access to food and water. The animals were acclimatized for one week before starting the experiment.

After acclimatization, 40 rats were randomly allocated into 5 groups $(n=8)$ as follows:

Group I (Control): received the vehicle.

Group II $\left(\mathrm{CuSO}_{4}\right)$ : received $100 \mathrm{mg} / \mathrm{kg} \mathrm{CuSO}_{4}[12,38]$.

Group III (DFO): received DFO (23 mg/kg) [39] and $100 \mathrm{mg} / \mathrm{kg} \mathrm{CuSO}_{4}$.

Group IV (CUR): received $80 \mathrm{mg} / \mathrm{kg}$ CUR [6,39] and $100 \mathrm{mg} / \mathrm{kg} \mathrm{CuSO}_{4}$.

Group V (N-CUR): received $80 \mathrm{mg} / \mathrm{kg} \mathrm{N}-\mathrm{CUR}[6,39]$ and $100 \mathrm{mg} / \mathrm{kg} \mathrm{CuSO}_{4}$.

$\mathrm{CuSO}_{4}, \mathrm{DFO}, \mathrm{CUR}$ and N-CUR were dissolved in $1 \% \mathrm{CMC}$ and supplemented via oral gavage for 7 days. The rats were sacrificed under ketamine/xylazine anesthesia, blood was collected, and the heart was removed, washed in cold phosphate buffered saline (PBS), and the parts of left ventricle were kept frozen in liquid nitrogen. Other samples from the heart were fixed in $10 \%$ neutral buffered formalin (NBF) while others were homogenized in $10 \mathrm{mM}$ ice-cold Tris-HCl buffer ( $\mathrm{pH}$ 7.4), centrifuged at $6000 \mathrm{rpm}$ for $10 \mathrm{~min}$ and the clear supernatant was used for the determination of malondialdehyde (MDA), GSH, superoxide dismutase (SOD), catalase (CAT), Bax, Bcl-2, caspase-3, TNF- $\alpha$, IL-6 and NF-kB p65.

\subsection{Determination of Cardiac Injury, $M D A$, and Antioxidants}

Serum cTnI was assayed using ELISA kit (MyBiosource, San Diego, CA, USA), and CK-MB and LDH were determined using reagent kits supplied by Spinreact (Girona, Spain), following the manufacturers' instructions.

Cardiac MDA was assayed as previously described [40]. Briefly, the heart tissue homogenate was mixed with TBA, SDS, and acetate buffer, and heated in boiling water bath for $60 \mathrm{~min}$. After cooling, $n$-butanol was added to the mixture, which was centrifuged, and absorbance of the organic layer was measured at $532 \mathrm{~nm}$. GSH was determined according to the method of Ellman [41]. This assay is based on the reaction of GSH with 5,5'-dithio-bis (2-nitrobenzoic acid) and measurement of the absorbance of the yellowcolored product at $412 \mathrm{~nm}$. Given its ability to inhibit pyrogallol autoxidation, SOD activity was determined following the method of Marklund and Marklund [42]. The activity of CAT was determined in the heart homogenate by monitoring the decomposition of hydrogen peroxide according to the method of Cohen et al. [43].

\subsection{Determination of NF- $\kappa B$ p65, Cytokines, Apoptosis Markers, and DNA Fragmentation}

Cardiac NF-kB p65, Bax and Bcl-2 were assayed using specific ELISA kits (MyBioSource, San Diego, CA, USA), and TNF- $\alpha$ and IL- 6 were assayed using R\&D Systems (Minneapolis, MN, USA) ELISA kits. Caspase-3 was determined in the heart homogenate using assay kit supplied by MyBioSource (San Diego, CA, USA). All assays were conducted according to the instructions of the manufacturers. Agarose electrophoresis and the colorimetric methods [44] were used to assess DNA fragmentation. The results were presented as a fold change of the control.

\subsection{Histological Examination}

The heart samples, fixed for $24 \mathrm{~h}$ in $10 \% \mathrm{NBF}$, were dehydrated, embedded in paraffin, and cut into $5-\mu \mathrm{m}$ thick-sections. The prepared sections were processed for staining with hematoxylin and eosin $(\mathrm{H} \& \mathrm{E})$ and were examined using a light microscope. 


\subsection{Gene Expression}

The effect of $\mathrm{CuSO}_{4}$ and treatment agents on the expression of cardiac activator protein-1 (AP-1) and BCL2 associated Athanogene (BAG)-1 were determined by qRT-PCR as previously described [45]. Briefly, RNA was isolated from the heart samples using TRIzol (ThermoFisher Scientific, Waltham, MA, USA), treated with RNase-free DNase (Qiagen, Hilden, Germany), quantified using a nanodrop, and samples with OD260/OD280 nm ratio of $\geq 1.8$ were reverse transcribed into cDNA. Amplification of cDNA was carried out using SYBR green master mix (ThermoFisher Scientific, Waltham, MA, USA) and the primers in Table 1 in a total reaction volume of $20 \mu \mathrm{L}$. The obtained data were analyzed using the $2^{-\Delta \Delta C t}$ method [46] and normalized to $\beta$-actin.

Table 1. Primers used for qRT-PCR.

\begin{tabular}{ccc}
\hline Gene & GenBank Accession Number & Primer Sequence $\left(5^{\prime} \mathbf{3}^{\prime}\right.$ ) \\
\hline \multirow{2}{*}{$A P-1$} & NM_021835.3 & F: TGGGCACATCACCACTACAC \\
& & R: GGGCAGCGTATTCTGGCTAT \\
BAG1 & NM_001106647.3 & F: GGTCCAGACGGAGGAAATGG \\
& R: ACTGTTACCTTGCTGTGGGG \\
$\beta$-actin & NM_031144.3 & F: AGGAGTACGATGAGTCCGGC \\
& R: CGCAGCTCAGTAACAGTCCG \\
\hline
\end{tabular}

\subsection{Western Blotting}

The frozen heart samples were homogenized in RIPA buffer supplemented with proteinase/phosphatase inhibitors, centrifuged, and the supernatant was collected. Protein concentration in the supernatant was assayed using Bradford protein assay kit (BioBasic, Markham, Canada), and $50 \mu \mathrm{g}$ protein was subjected to 10\% SDS/PAGE and electrotransferred to nitrocellulose membranes. The membranes were blocked in $5 \%$ milk in TBST followed by incubation overnight at $4{ }^{\circ} \mathrm{C}$ with primary antibodies against TLR4, p-p38 MAPK, p38 MAPK, pJNK, JNK, pERK1/2, ERK1/2, and $\beta$-actin. The membranes were washed, probed with secondary antibodies, washed with TBST, and developed using Clarity ${ }^{\mathrm{TM}}$ Western ECL Substrate from BIO-RAD (Hercules, CA, USA). The bands were visualized in ImageQuant LAS 4000 and quantified using ImageJ (version 1.32j, NIH, USA).

\subsection{Statistical Analysis}

The results are expressed as mean \pm standard deviation (SD). Statistical analysis and multiple comparisons were performed by one-way analysis of variance (ANOVA) and Tukey's post-hoc test using GraphPad Prism 8. A $p$ value $<0.05$ was considered significant.

\section{Results}

\subsection{N-CUR and CUR Prevent Cu-Induced Cardiac Injury in Rats}

The cardioprotective effect of CUR and N-CUR against $\mathrm{Cu}$ toxicity was evaluated through the assessment of circulating cardiac function markers (cTnI, CK-MB, and LDH) and histopathological investigation. Cu-exposed rats exhibited significantly elevated serum cTnI (Figure 1A), CK-MB (Figure 1B) and LDH (Figure 1C) as compared to the control rats $(p<0.001)$. Treatment of the $\mathrm{Cu}$-exposed rats with DFO, CUR, or N-CUR ameliorated serum cTnI, CK-MB, and LDH significantly $(p<0.001)$. The effect of $\mathrm{N}-\mathrm{CUR}$ on serum CK-MB and LDH was significant when compared with DFO $(p<0.01 ; p<0.001)$ and CUR $(p<0.05 ; p<0.05)$. 
A

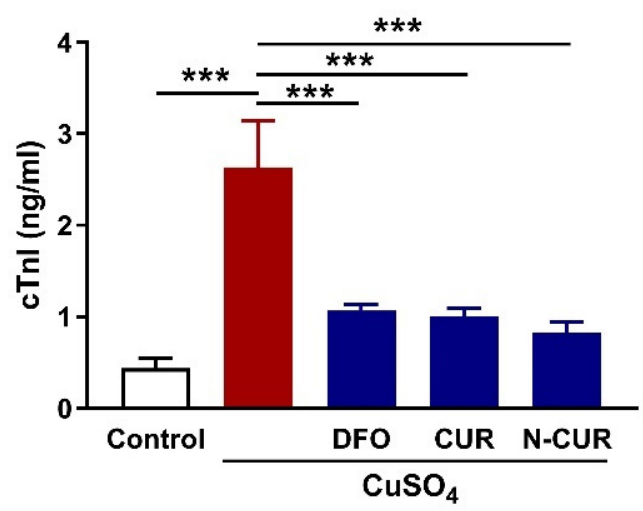

B

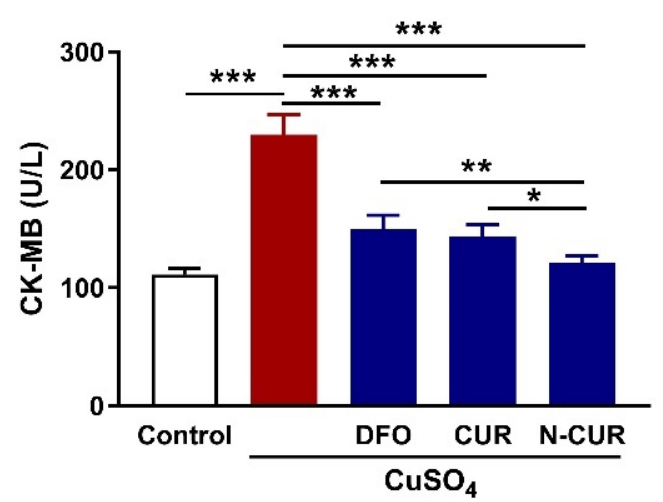

C

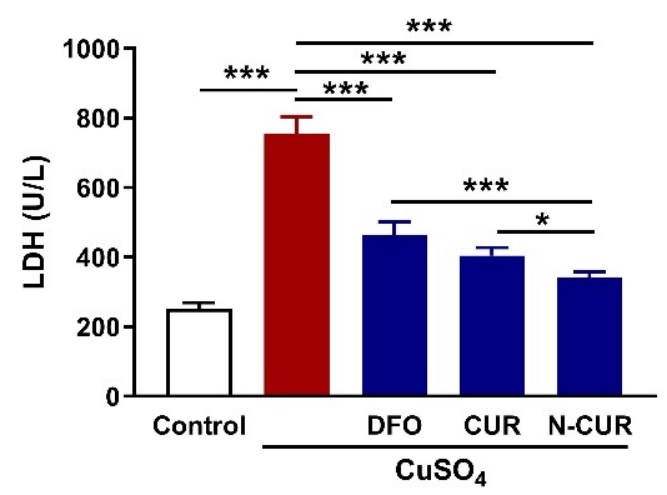

Figure 1. N-CUR and CUR prevent Cu-induced cardiac injury in rats. Treatment with N-CUR, CUR, and DFO ameliorated serum cardiac troponin I (cTnI) (A), creatine kinase (CK)-MB (B) and lactate dehydrogenase $(\mathrm{LDH})(\mathrm{C})$. Data are mean $\pm \mathrm{SD},(n=8) .{ }^{*} p<0.05,{ }^{* *} p<0.01$ and ${ }^{* * *} p<0.001$.

The histopathological investigation showed normal morphological appearance with normal cardiomyocytes in the control group (Figure 2A). In contrast, $\mathrm{Cu}$ administration induced the appearance of blood vessel congestions, inflammatory cells infiltration and degenerative changes as shown in Figure 2B,C. In parallel with the biochemical findings, sections in the heart of Cu-exposed rats treated with DFO (Figure 2D), CUR (Figure 2E), and N-CUR (Figure 2F) showed no histopathological alterations. 

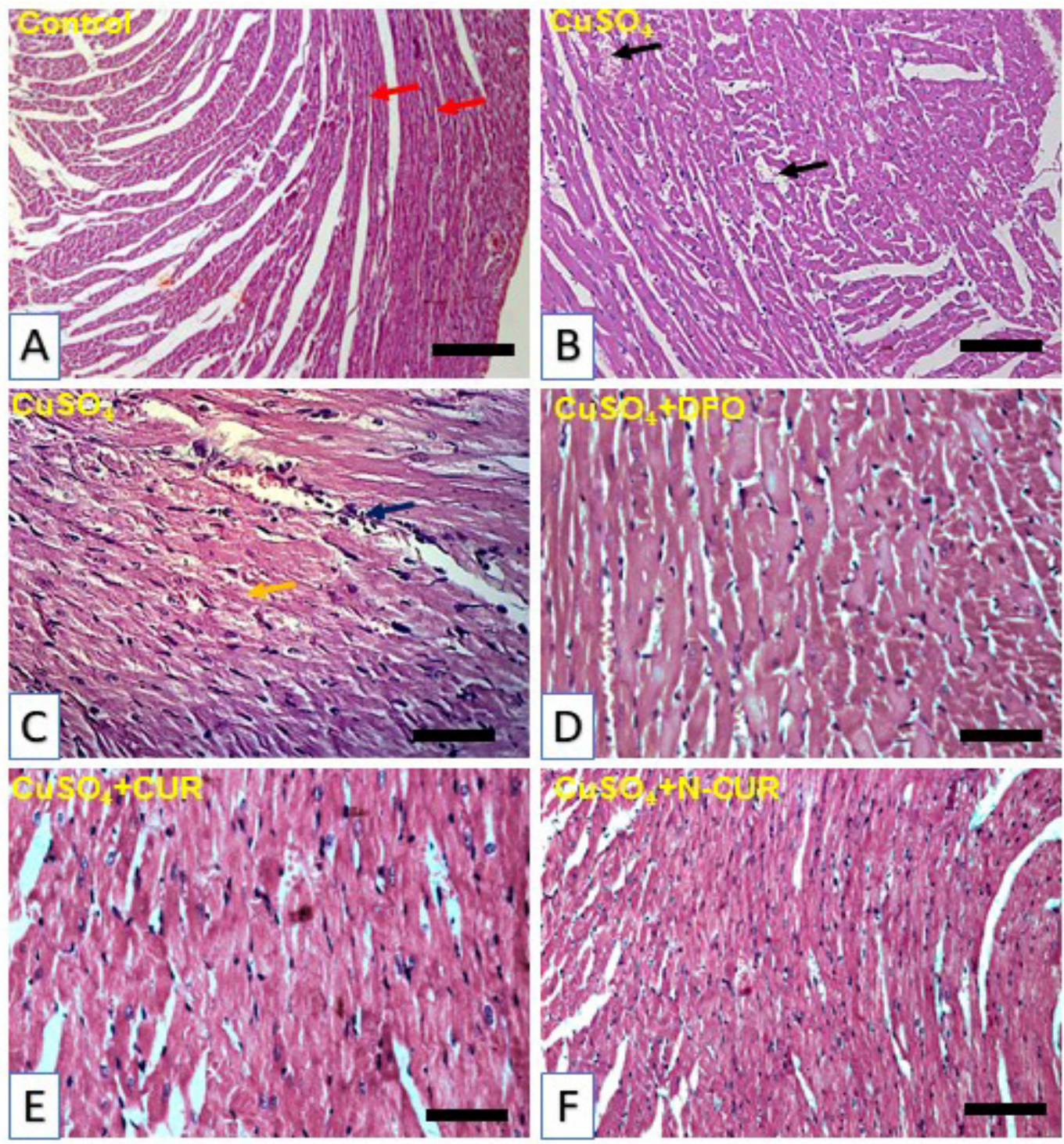

Figure 2. Photomicrographs of H\&E-stained sections in the heart of (A) control rats showing normal histological structure of the cardiomyocytes (red arrow), (B,C) $\mathrm{CuSO}_{4}$-intoxicated rats showing blood vessel congestions (black arrow), inflammatory cell infiltration (blue arrow) and degenerative changes (yellow arrow), (D,F) $\mathrm{CuSO}_{4}$-intoxicated rats treated with deferoxamine (DFO) (D), curcumin (CUR) (E), and nano-CUR (N-CUR) (F) showing no histopathological alterations. (Scale bar $=50 \mu \mathrm{m},-400 \mathrm{X}$ ).

\subsection{N-CUR and CUR Attenuate Cardiac Oxidative Stress in Cu-Induced Rats}

Cardiac lipid peroxidation (LPO), assessed as MDA, was significantly elevated in Cuintoxicated rats when compared with the control group ( $p<0.001$; Figure $3 \mathrm{~A})$. The content of the cellular antioxidant GSH (Figure 3B), as well as the activities of SOD (Figure 3C) and CAT (Figure 3D), were markedly decreased in the heart of $\mathrm{Cu}$-intoxicated rats $(p<0.001)$. DFO, CUR, and N-CUR decreased MDA and increased GSH and SOD in the heart of Cutreated rats. The effect of N-CUR on cardiac MDA and GSH was significant as compared to DFO $(p<0.001 ; p<0.001)$ and CUR $(p<0.05 ; p<0.01)$. 
A

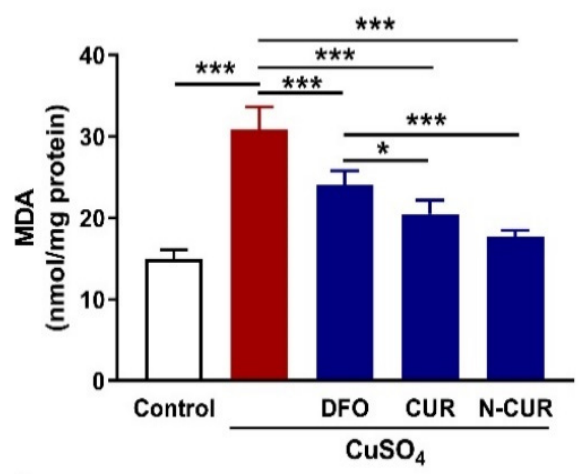

C

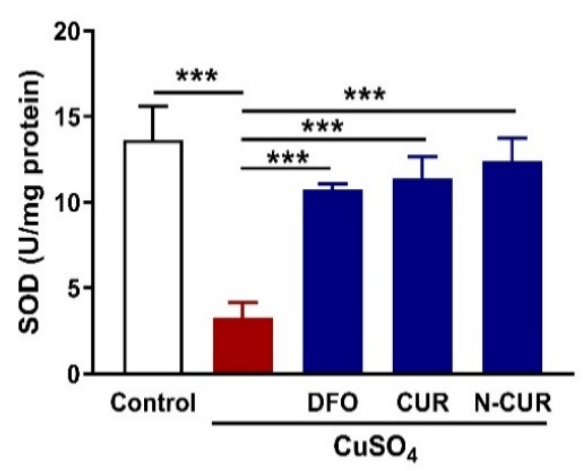

B

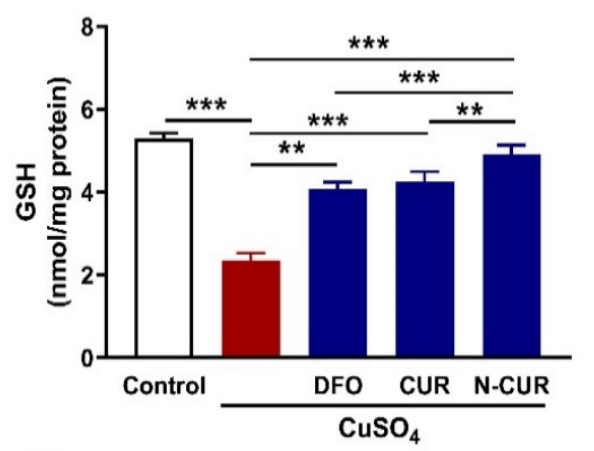

D

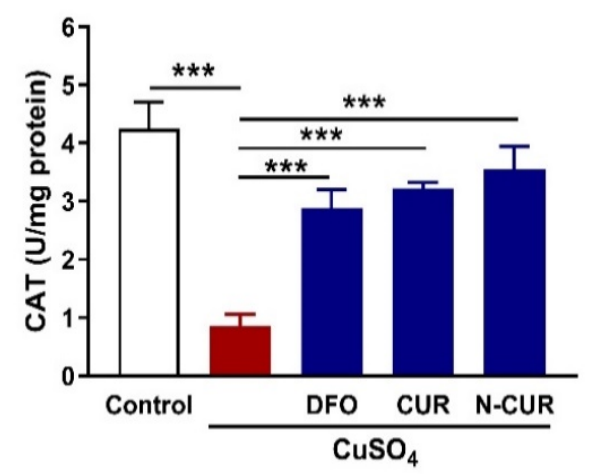

Figure 3. N-CUR and CUR attenuate cardiac oxidative stress in $\mathrm{Cu}$-intoxicated rats. Treatment with N-CUR, CUR, and DFO decreased cardiac MDA (A) and increased GSH (B), SOD (C), and CAT (D). Data are mean $\pm \mathrm{SD},(n=8) .{ }^{*} p<0.05,{ }^{* *} p<0.01$ and ${ }^{* * *} p<0.001$.

\subsection{N-CUR and CUR Suppress Cardiac TLR4/NF- $\kappa B$ and MAPK Signaling in Cu-Induced Rats}

The protein expression of TLR4 was significantly upregulated in the heart of rats that received $\mathrm{Cu}(p<0.001)$ as depicted in Figure 4A,B. Treatment with DFO, CUR, and N-CUR significantly downregulated TLR4 in the heart of Cu-exposed rats. N-CUR downregulated cardiac TLR4 expression significantly when compared with DFO or CUR.

To evaluate changes in the intracellular signaling in $\mathrm{Cu}$-exposed rats and the modulatory role of DFO, CUR, and N-CUR, the phosphorylation levels of p38 MAPK, JNK, and ERK1/2 were determined using Western blotting. $\mathrm{Cu}$ increased the phosphorylation levels of p38 MAPK (Figure 4C), JNK (Figure 4D) and ERK1/2 (Figure 4E) in the heart of rats significantly as compared to the control animals $(p<0.001)$. All treatment agents effectively decreased the phosphorylation levels of cardiac p38 MAPK, JNK, and ERK1/2 in $\mathrm{Cu}$-intoxicated rats $(p<0.001)$. N-CUR decreased the phosphorylation of p38 MAPK significantly when compared with CUR $(p<0.01)$, and pJNK $(p<0.001)$ and pERK1/2 $(p<0.001)$ when compared with either DFO or CUR.

Additionally, NF-KB p65 was significantly increased in the heart of $\mathrm{Cu}$-treated rats $(p<0.001)$ and decreased in rats that received DFO, CUR, or N-CUR as represented in Figure 4F. When compared with DFO or CUR, N-CUR was more effective in downregulating cardiac NF-kB p65 in Cu-intoxicated rats ( $p<0.01$ and $p<0.05$, respectively). 


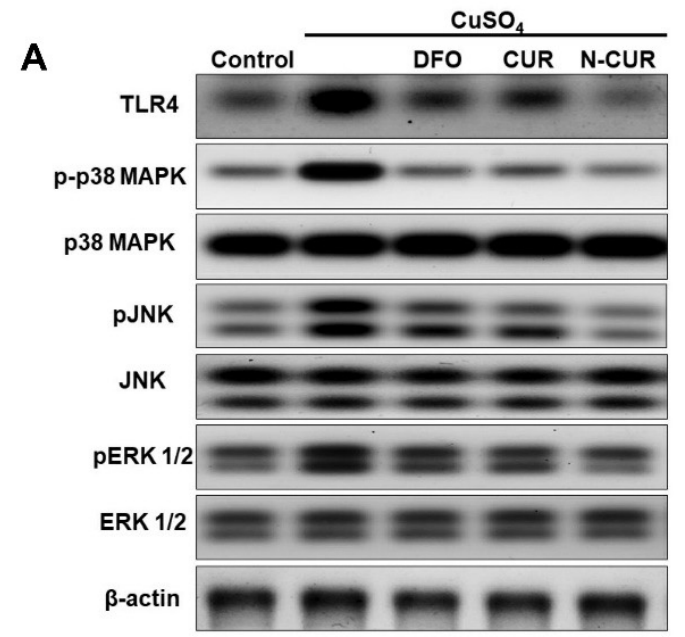

B

C
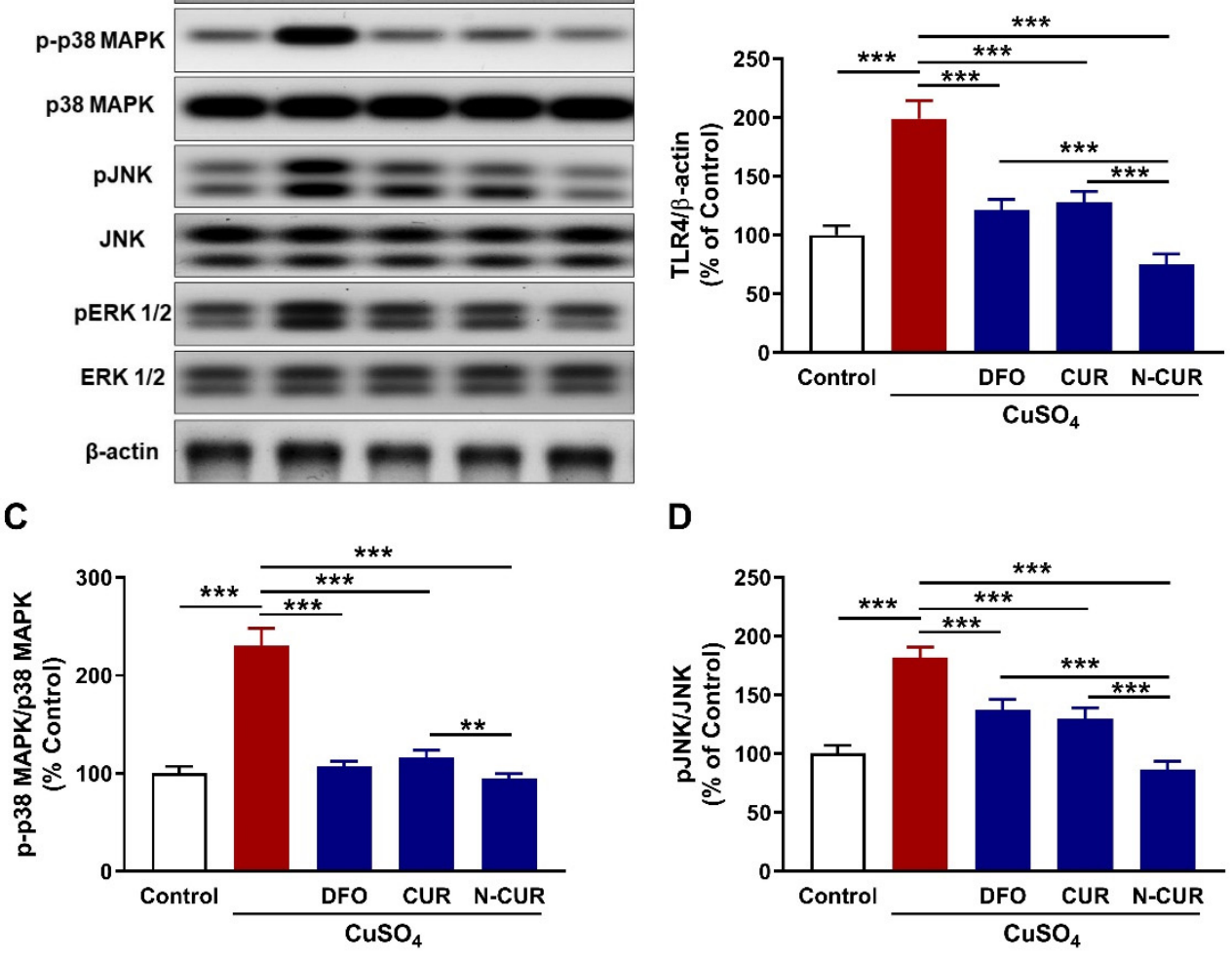

D

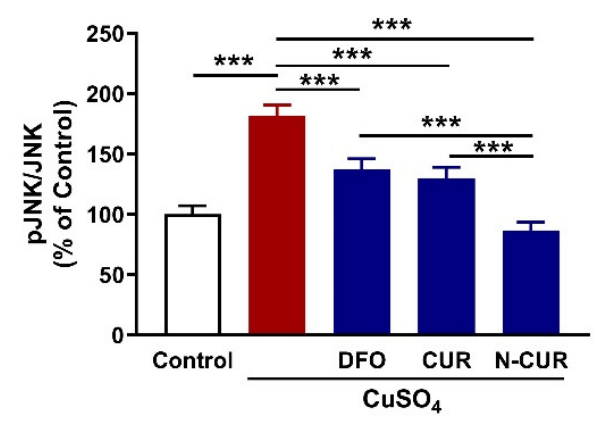

E

$\mathbf{F}$
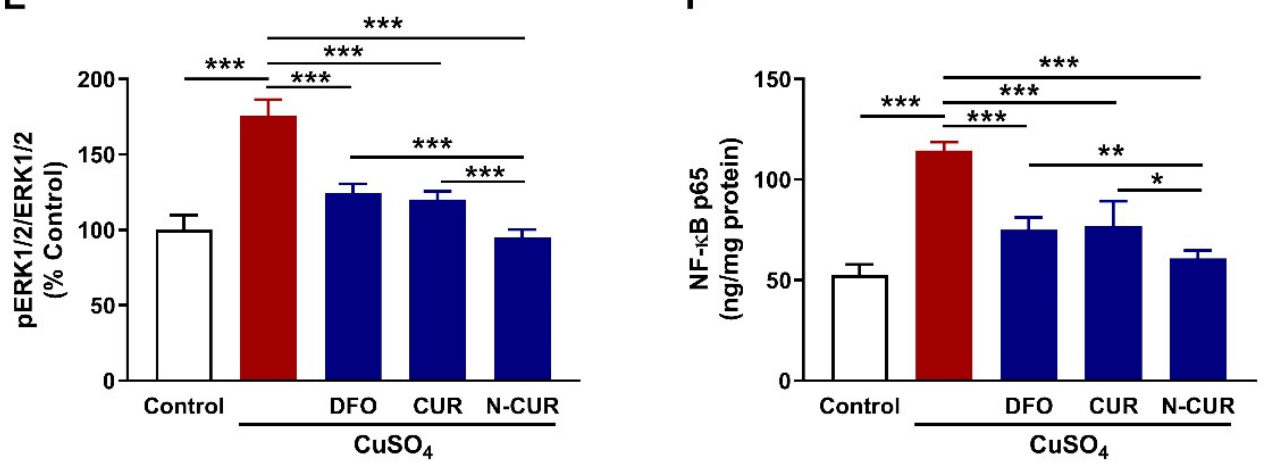

Figure 4. N-CUR and CUR suppress cardiac TLR4/NF- $\mathrm{BB}$ and MAPK signaling in Cu-intoxicated rats. (A) Representative blots showing changes in the expression of TLR4, p38 MPAK, JNK, ERK1/2, and $\beta$-actin. (B-F) N-CUR, CUR, and DFO downregulated cardiac TLR4 (B) and decreased the phosphorylation levels of p38 MAPK (C), JNK (D), ERK1/2 (E), and NF-KB (F). Data are mean \pm SD, $(n=8) .{ }^{*} p<0.05,{ }^{* *} p<0.01$ and ${ }^{* * *} p<0.001$.

\subsection{N-CUR and CUR Mitigate Cardiac AP-1, TNF- $\alpha$, and IL-6 in Cu-Induced Rats}

Exposure of the rats to $\mathrm{Cu}$ increased AP-1 mRNA abundance in the heart significantly $(p<0.001)$ as compared to the control rats (Figure 5A). In the same context, cardiac levels of TNF- $\alpha(p<0.001)$ and IL-6 $(p<0.001)$ were increased in Cu-exposed rats as represented in Figure 5B,C, respectively. Treatment of the Cu-exposed rats with DFO, CUR, or N-CUR downregulated cardiac AP-1 mRNA and decreased TNF- $\alpha$ and IL-6 $(p<0.001)$. N-CUR decreased AP-1 significantly when compared with DFO $(p<0.01)$, and TNF- $\alpha$ and IL- 6 as compared with either DFO $(p<0.01$ and $p<0.05)$ or CUR $(p<0.05$ and $p<0.05)$. 


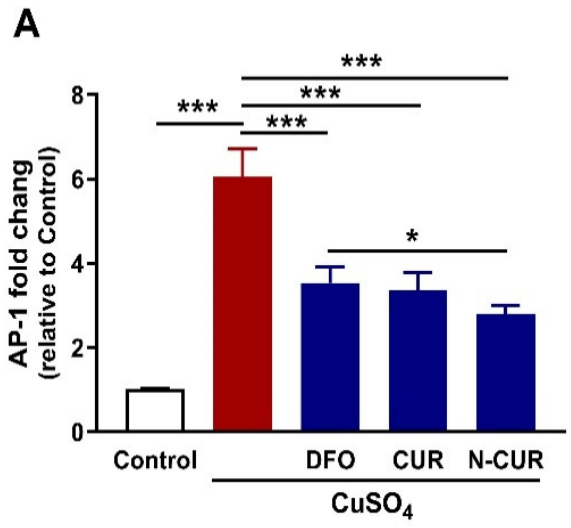

B

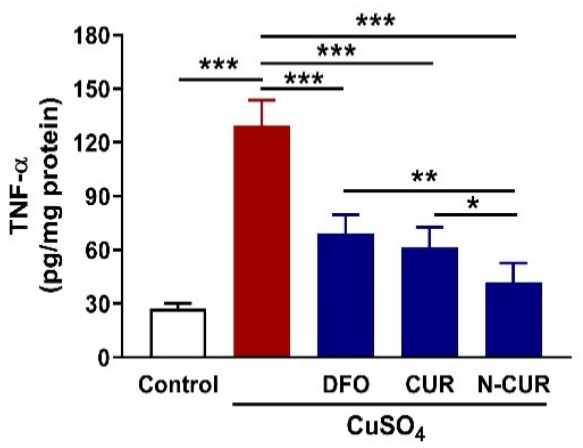

C

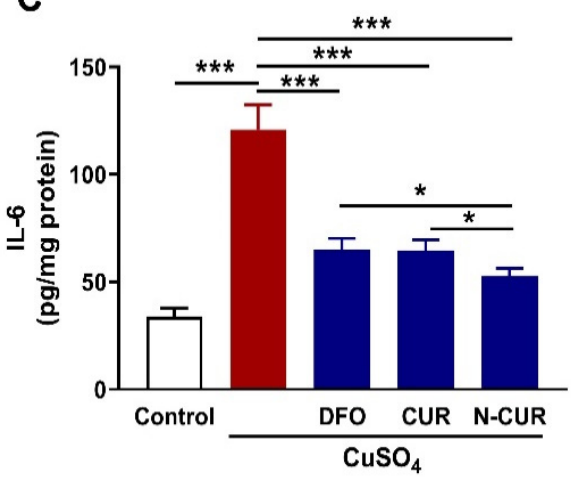

Figure 5. N-CUR and CUR downregulated cardiac AP-1 mRNA abundance (A), TNF- $\alpha$ (B) and IL-6 (C) in Cu-intoxicated rats. Data are mean $\pm \mathrm{SD},(n=8)$. ${ }^{*} p<0.05,{ }^{* *} p<0.01$ and ${ }^{* *} p<0.001$.

\subsection{N-CUR and CUR Prevent Apoptosis in Cu-Intoxicated Rats}

The expression levels of Bcl-2, BAG-1, Bax, and caspase-3 were assessed to evaluate the protective effect of CUR, and N-CUR on Cu-induced cardiomyocyte apoptosis. Bcl-2 (Figure 6A) and BAG-1 (Figure 6B) were significantly downregulated in the heart of $\mathrm{Cu}$ intoxicated rats as compared to the control group $(p<0.001)$. DFO, CUR, and N-CUR upregulated cardiac Bcl-2 protein and BAG-1 mRNA abundance in Cu-treated rats. Bax (Figure 6C) and caspase-3 (Figure 6D) showed significant increase in the heart of rats exposed to $\mathrm{Cu}$ as compared to the control group $(p<0.001)$, effects that were reversed in rats that received DFO, CUR, or N-CUR. The effect of N-CUR on Bcl-2, BAG-1, Bax, and caspase-3 was significant when compared with either CUR or DFO.

The protective effect of CUR and N-CUR against $\mathrm{Cu}$-induced cardiomyocyte cell death was further confirmed via assessment of DNA fragmentation (Figure 6E,F). Cu-intoxicated rats showed an increase in DNA fragmentation levels as compared to the control group $(p<0.001)$. All treatments (DFO, CUR, and N-CUR) prevented the deleterious effect of $\mathrm{Cu}$ on DNA integrity. N-CUR effectively decreased DNA fragmentation when compared with CUR or DFO $(p<0.05)$. 
A

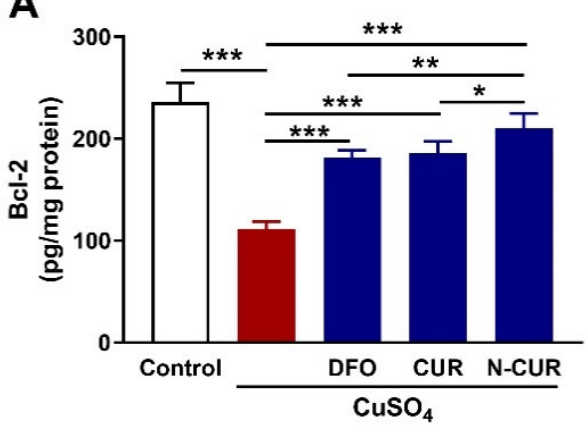

C

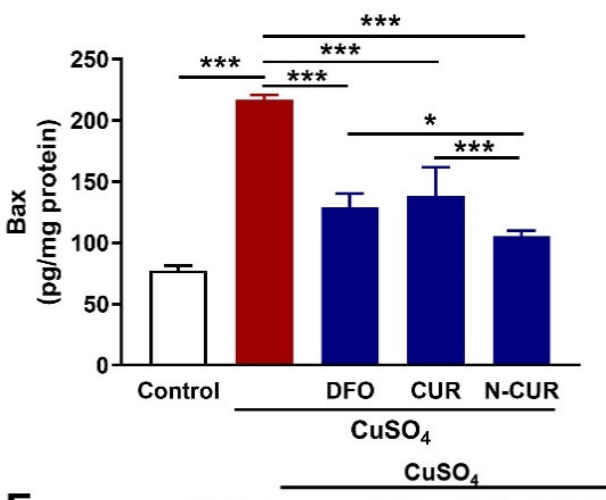

E

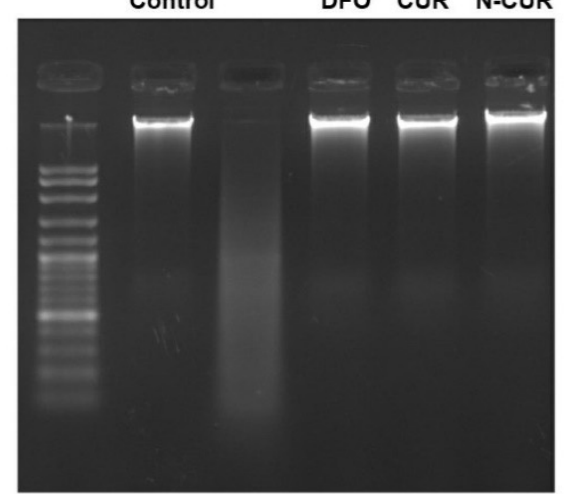

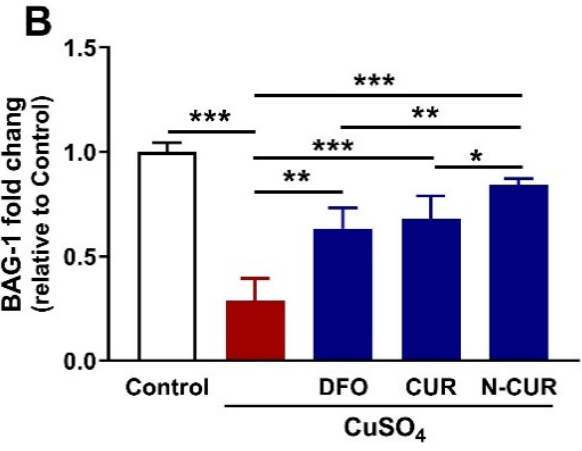

D

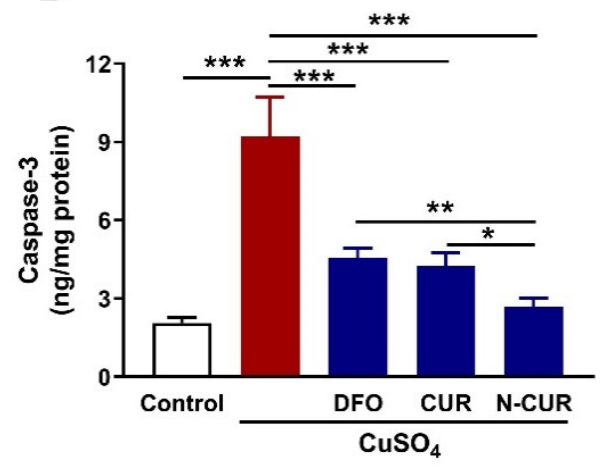

$\mathbf{F}$

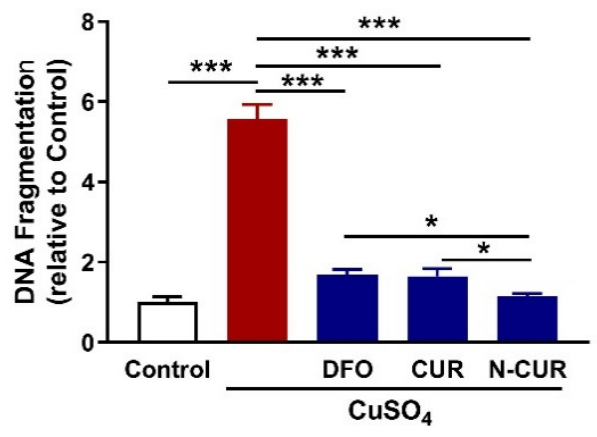

Figure 6. N-CUR and CUR prevent apoptosis in Cu-intoxicated rats. N-CUR, CUR, and DFO increased cardiac Bcl-2 (A) and BAG-1 mRNA (B), decreased Bax (C), and caspase-3 (D), and prevented DNA fragmentation $(\mathbf{E}, \mathbf{F})$ in Cu-intoxicated rats. Data are mean $\pm \mathrm{SD},(n=8) .{ }^{*} p<0.05,{ }^{* *} p<0.01$ and ${ }^{* * *} p<0.001$.

\section{Discussion}

Copper is an essential element for a plethora of cellular processes and plays a key role as a catalytic factor for many enzymes, such as SOD and cytochrome c oxidase [2]. Cu is present in both oxidized and reduced forms and its high redox reactivity makes it a source of ROS and makes it potentially toxic [20]. Cu can disturb the redox homeostasis, and provoke oxidative stress and cellular damage, leading to several diseases. Hepatotoxicity, kidney injury, and neurodegenerative disorders were associated with the exposure to $\mathrm{Cu}[7-10,12]$; however, the toxic effects of $\mathrm{Cu}$ on the heart are less documented. Herein, we evaluated the possible involvement of oxidative stress, and TLR4/NF- $\mathrm{KB}$ and MAPK signaling, in the cardiotoxic effect of $\mathrm{Cu}$ in rats, and the protective effect of CUR and N-CUR.

Exposure to $\mathrm{CuSO}_{4}$ caused cardiac injury manifested by the elevated circulating cTnI, $\mathrm{CK}-\mathrm{MB}$, and LDH. CTnI is a highly specific and sensitive marker for myocardial injury, and increased serum CK-MB and LDH denotes myocardial damage [47]. In support of the biochemical findings, the histopathological examination revealed congestions, degenera- 
tive changes, and inflammatory cell infiltrations in the myocardium of $\mathrm{CuSO}_{4}$-treated rats. $\mathrm{CuSO}_{4}$ is a pesticide used for repelling pests in agriculture and for minimizing contamination risk in tissue culture incubators due to its bactericidal and fungicidal properties [48]. Accidental intoxication among farm workers exposed to $\mathrm{CuSO}_{4}$ has been reported, and toxic levels of this pesticide can lead to methemoglobinemia and death [48]. Cardiotoxicity due to exposure to $\mathrm{Cu}$ has been reported in zebrafish [5,16], and increased incidence of $\mathrm{HF}$ in human was associated with high Cu levels [17-19]. Owing to its ability to generate ROS, cardiotoxicity of $\mathrm{Cu}$ could be directly attributed to oxidative stress. The present study showed an increase in cardiac LPO and decreased GSH and antioxidant enzymes (SOD and CAT), demonstrating an oxidative stress status. The redox nature of $\mathrm{Cu}$ renders it toxic due to the generation of highly reactive hydroxyl radicals $(\bullet \mathrm{OH})$ [20]. In addition, $\mathrm{Cu}$ can alter the activity of respiratory chain enzymes resulting in increased mitochondrial ROS generation [21]. ROS are potent oxidizing agents that provoke oxidative damage of cellular macromolecules and cell death $[23,24]$. Accordingly, oxidative stress has been reported in the hippocampus of rats following the administration of $\mathrm{CuSO}_{4}$ [25] and $\mathrm{Cu}$ chloride [10]. The current study introduced information on the involvement of oxidative stress in $\mathrm{CuSO}_{4}$ cardiotoxicity in rats.

CUR and N-CUR ameliorated serum CTnI, CK-MB, and LDH, and prevented all histopathological alterations in the heart of $\mathrm{CuSO}_{4}$-intoxicated rats. Since oxidative stress plays the key role in $\mathrm{Cu}$ toxicity, the cardioprotective effect of CUR is a direct consequence of its radical-scavenging and antioxidant properties. Here, rats that received CUR and $\mathrm{N}$-CUR exhibited remarkable reduction in cardiac LPO and enhanced GSH, SOD, and CAT. The antioxidant activity of CUR has been reported in several studies of experimental cardiotoxicity induced by doxorubicin, daunorubicin, cisplatin, cyclophosphamide, irinotecan, bisphenol, atrazine, and isoproterenol (reviewed in [49]). CUR protected rats against liver and kidney injury induced by $\mathrm{CuSO}_{4}$ through the suppression of MDA and enhancement of antioxidants [6], and prevented $\mathrm{CuSO}_{4}$-induced oxidative stress in Drosophila melanogaster [50]. Besides its radical-scavenging properties, CUR can activate Nrf2, which is a redox-sensitive factor that regulates antioxidant genes and suppresses oxidative stress [51]. CUR is a potent Nrf2 activator, and studies have shown upregulation of Nrf2-dependent antioxidant genes following its administration [29,52,53].

Besides attenuation of oxidative stress, CUR and N-CUR suppressed the inflammatory response elicited by $\mathrm{CuSO}_{4}$ in the heart of rats. $\mathrm{CuSO}_{4}$ promoted the activation of TLR4/NF$\mathrm{KB}$ and MAPK signaling in the heart of rats. Consequently, an increase in the levels of pro-inflammatory cytokines (TNF- $\alpha$ and IL-6) was reported, pinpointing cardiomyocyte inflammation. Activation of TLR4 signaling in the heart of $\mathrm{Cu}$-intoxicated rats is a direct consequence of excessive ROS generation and cell injury [34]. Activation of TLR4 occurs in cardiotoxicity, cardiomyopathy, HF, and other cardiac alterations [36]. TLR4 triggers both the MyD88-dependent and -independent pathways, leading to the activation of transcription factors such as NF- $\mathrm{kB}$ and the production of pro-inflammatory mediators [35]. MyD88 recruits and activate IL-1 receptor-associated kinases (IRAKs), which in turn activate TNF receptor-associated factor 6 (TRAF6), and then TAK1 is activated [54]. TAK1 phosphorylates both MAPKs and the IKK complex. It induces I $\kappa$ B phosphorylation leading to NF- $\mathrm{KB}$ activation and translocation into the nucleus to promote the expression of proinflammatory cytokines. TAK1 also activates p38 MAPK, JNK, and ERK1/2 and the activated MAPK signaling activates the transcription factor AP-1, which contributes to the release of pro-inflammatory cytokines [54]. In the present study, TLR4 was upregulated, and the phosphorylation levels of NF- $\mathrm{kB}$, p38 MAPK, JNK, and ERK1/2 were increased in the heart of $\mathrm{CuSO}_{4}$-induced rats. Consequently, the expression of TNF- $\alpha$ and IL-6 was upregulated.

CUR and N-CUR effectively suppressed the cardiac inflammatory response triggered by $\mathrm{CuSO}_{4}$ in rats, demonstrating a potent anti-inflammatory activity. CUR can effectively inhibit TLR4 homodimerization, which is the initial step in activating the inflammatory response [55]. This supported the suppression of TLR4 signaling in the heart of $\mathrm{CuSO}_{4^{-}}$ 
induced rats treated with CUR. CUR has anti-inflammatory activities and downregulates MAPKs, TNF- $\alpha$, and IL-6 [55]. It can inhibit both MyD88- and TRIF-dependent pathways [55], and computational approaches have revealed that it can fit into the myeloid differentiation factor 2 (MD2) pocket [56]. Given the role of oxidative stress in activating TLR4, the ameliorative effect of CUR could be attributed to its ability to suppress both oxidative stress and TLR4-mediated inflammatory response. The anti-inflammatory effect of CUR has also been supported by studies employing experimental models of cardiotoxicity [49].

CUR and N-CUR prevented apoptotic cell death in the heart of $\mathrm{CuSO}_{4}$-induced rats, adding support to their cardioprotective activities. Apoptotic cell death was observed in the heart of $\mathrm{Cu}$-administered rats in the present study where Bcl-2 and BAG-1 were downregulated, and Bax and caspase- 3 were upregulated. Cell death due to $\mathrm{Cu}$ intoxication could be directly attributed to the provoked oxidative stress and inflammatory response. $\mathrm{Cu}$-mediated ROS can induce mitochondrial permeability transition in different cells, including astrocytes [57] and hepatocytes [58], leading to apoptotic cell death. In addition, surplus ROS can activate the pro-apoptotic protein Bax, which induce the release of mitochondrial cytochrome $c$ by promoting the loss of mitochondrial membrane potential via voltage-dependent anion channel [59]. Through interaction with Apaf, cytochrome $c$ can initiate the activation cascade of caspases. Caspase- 3 is the executioner caspase that elicits DNA fragmentation or degradation of cytoskeletal proteins, culminating in cell death [60]. The active caspase- 3 itself favors further release of cytochrome $c$ from the mitochondria and amplification of the death signal [60]. Accordingly, analysis of DNA fragmentation revealed a significant increase in the heart of $\mathrm{CuSO}_{4}$-intoxicated rats. In contrast, $\mathrm{Bcl}-2$ and BAG-1 were decreased in the heart of rats that received $\mathrm{CuSO}_{4}$. Bcl-2 suppresses the release of cytochrome $c$ and prevents apoptosis [61], and BAG-1 is a multifunctional protein that synergizes the action of Bcl-2 to suppress cell death [62]. CUR upregulated the anti-apoptotic factors Bcl-2 and BAG-1, suppressed Bax and caspase-3, and prevented DNA fragmentation, demonstrating a potent anti-apoptotic effect, which is a direct consequence of its antioxidant and anti-inflammatory properties.

$\mathrm{N}$-CUR exerted a significant modulatory effect on cardiac function markers, LPO, GSH, TLR4, pro-inflammatory cytokines, phosphorylation levels of NF- $\mathrm{kB}$, p38 MAPK, JNK, and ERK1/2, apoptosis markers, and DNA fragmentation when compared with CUR. The superior effect of N-CUR is a direct result of the improved properties of CUR. Despite its reported pharmacological effects, the therapeutic applications of CUR are limited by its poor water solubility, absorption and systemic bioavailability, rapid metabolism, physicochemical instability, and low penetration and targeting efficacy [37]. This notion is supported by studies showing the stronger antioxidant and anti-inflammatory properties of N-CUR. For instance, N-CUR displayed stronger radical-scavenging and anti-LPO properties than the native compound in hepatoma cells lines [63]. CUR nanoparticles showed better solubility and downregulated NF- $\mathrm{kB}$ and pro-inflammatory mediators in LPS-challenged macrophages than the native form [64].

\section{Conclusions}

These results confer information on the cardiotoxic effect of $\mathrm{Cu}$ and the protective effect of CUR and its nanoform. N-CUR and CUR ameliorated cardiac function markers, and attenuated cardiac tissue injury, oxidative stress, inflammation, and cell death in $\mathrm{Cu}$ intoxicated rats. These beneficial effects were associated with suppression of TLR4/NF- $\mathrm{kB}$ and MAPKs signaling (Figure 7). N-CUR exerted a stronger cardioprotective efficacy as compared to the native form, an effect that could be explained in terms of improved properties of CUR. Therefore, N-CUR can confine the cardiotoxicity of $\mathrm{CuSO}_{4}$ by attenuating oxidative damage, inflammation, and apoptosis, pending further studies to explore other involved mechanisms. 


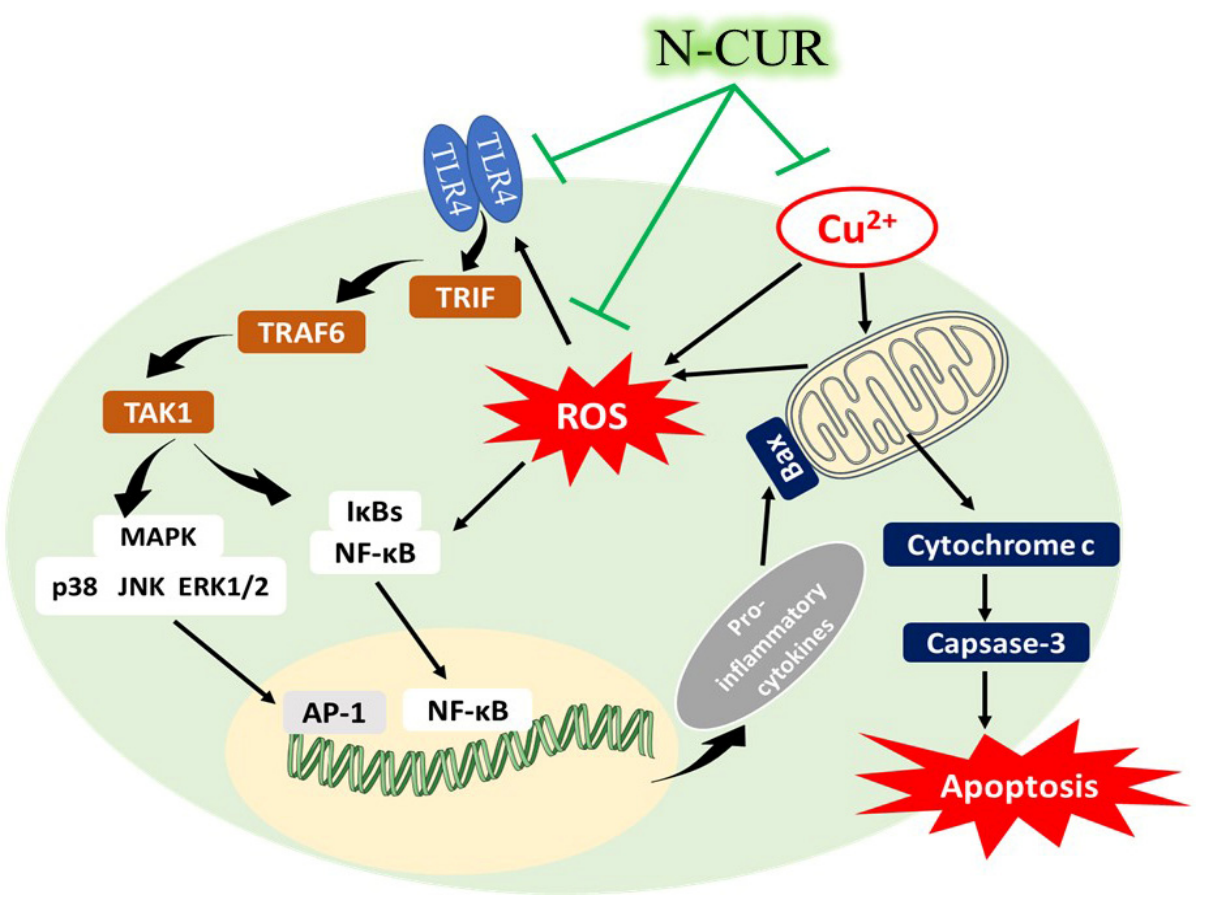

Figure 7. A schematic diagram illustrating the cardiotoxic effect of $\mathrm{Cu}$ and the protective effect of N-CUR. Cu elicits the generation of ROS and activates TLR4, NF-kB and MAPKs, leading to the release of pro-inflammatory cytokines and apoptotic cell death. N-CUR prevented Cu-induced cardiac tissue injury by suppressing oxidative stress, inflammation and cell death, effects that were associated with suppression of TLR4/NF-KB and MAPKs signaling.

Author Contributions: Conceptualization, W.S.S.; A.M.A. (Ahlam M. Alhusaini) and A.M.M.; methodology, W.S.S.; A.M.A. (Ahlam M. Alhusaini); L.M.F.; H.A.A.; A.B.A.; A.S.A.; I.H.H. and A.M.M.; validation, W.S.S.; A.M.A. (Ahlam M. Alhusaini) and A.M.M.; formal analysis, W.S.S.; A.M.A. (Ahlam M. Alhusaini) and A.M.M.; investigation, W.S.S.; A.M.A. (Ahlam M. Alhusaini); L.M.F.; H.A.A.; A.B.A.; I.H.H. and A.M.M.; resources, W.S.S.; A.M.A. (Ahlam M. Alhusaini); A.M.A. (Areej M. Alotaibi) and A.M.M.; data curation, W.S.S. and A.M.M.; writing-original draft preparation, A.M.M.; writing - review and editing, A.M.M.; visualization, W.S.S.; A.M.A. (Ahlam M. Alhusaini); I.H.H. and A.M.M.; supervision, A.M.A. (Ahlam M. Alhusaini) and A.M.M.; project administration, A.M.A. (Ahlam M. Alhusaini); I.H.H. and W.S.S.; funding acquisition, A.M.A. (Ahlam M. Alhusaini) and W.S.S. All authors have read and agreed to the published version of the manuscript.

Funding: This research was funded by the Deanship of Scientific Research at King Saud University, grant number RG-1441-546.

Institutional Review Board Statement: The experiment was conducted according to the guidelines of the National Institutes of Health (NIH publication No. 85-23, revised 2011) and was approved by the research ethics Committee at King Saud University (Ethical reference no. SE-19-129).

Informed Consent Statement: Not applicable.

Data Availability Statement: Data analyzed or generated during this study are included in this manuscript.

Acknowledgments: The authors extend their appreciation to the Deanship of Scientific Research at King Saud University for funding this work through research group number RG-1441-546.

Conflicts of Interest: The authors declare no conflict of interest.

\section{References}

1. Scheiber, I.F.; Mercer, J.F.; Dringen, R. Metabolism and functions of copper in brain. Prog. Neurobiol. 2014, 116, 33-57. [CrossRef] [PubMed]

2. Uriu-Adams, J.Y.; Keen, C.L. Copper, oxidative stress, and human health. Mol. Asp. Med. 2005, 26, 268-298. [CrossRef] [PubMed] 
3. Denoyer, D.; Masaldan, S.; La Fontaine, S.; Cater, M.A. Targeting copper in cancer therapy: 'Copper That Cancer'. Metallomics 2015, 7, 1459-1476. [CrossRef] [PubMed]

4. Zietz, B.; Dassel de Vergara, J.; Schneider, H.; Kessler, B.; Dunkelberg, H. Prevalence of elevated copper concentrations in tap water in two areas of Germany used for infant feeding and possible health implications. Eur. J. Med. Res. 1999, 4, 298.

5. Hsiao, C.-D.; Wu, H.-H.; Malhotra, N.; Liu, Y.-C.; Wu, Y.-H.; Lin, Y.-N.; Saputra, F.; Santoso, F.; Chen, K.H.-C. Expression and Purification of Recombinant GHK Tripeptides Are Able to Protect against Acute Cardiotoxicity from Exposure to WaterborneCopper in Zebrafish. Biomolecules 2020, 10, 1202. [CrossRef]

6. Hashish, E.A.; Elgaml, S.A. Hepatoprotective and Nephroprotective Effect of Curcumin Against Copper Toxicity in Rats. Indian J. Clin. Biochem. IJCB 2016, 31, 270-277. [CrossRef]

7. Brewer, G.J. Alzheimer's disease causation by copper toxicity and treatment with zinc. Front. Aging Neurosci. 2014, 6, 92. [CrossRef]

8. Montes, S.; Rivera-Mancia, S.; Diaz-Ruiz, A.; Tristan-Lopez, L.; Rios, C. Copper and copper proteins in Parkinson's disease. Oxid. Med. Cell. Longev. 2014, 2014, 147251. [CrossRef] [PubMed]

9. Committee on Copper in Drinking Water. Copper in Drinking Water; National Academy Press: Washington, DC, USA, 2001.

10. Lamtai, M.; Zghari, O.; Ouakki, S.; Marmouzi, I.; Mesfioui, A.; El Hessni, A.; Ouichou, A. Chronic copper exposure leads to hippocampus oxidative stress and impaired learning and memory in male and female rats. Toxicol. Res. 2020, 36, 359-366. [CrossRef]

11. Gamakaranage, C.S.; Rodrigo, C.; Weerasinghe, S.; Gnanathasan, A.; Puvanaraj, V.; Fernando, H. Complications and management of acute copper sulphate poisoning; a case discussion. J. Occup. Med. Toxicol. 2011, 6, 34. [CrossRef]

12. Kumar, V.; Kalita, J.; Misra, U.K.; Bora, H.K. A study of dose response and organ susceptibility of copper toxicity in a rat model. J. Trace Elem. Med. Biol. 2015, 29, 269-274. [CrossRef]

13. Lawson, M.K.; Valko, M.; Cronin, M.T.D.; Jomová, K. Chelators in Iron and Copper Toxicity. Curr. Pharmacol. Rep. 2016, 2, 271-280. [CrossRef]

14. Alanazi, A.M.; Fadda, L.; Alhusaini, A.; Ahmad, R.; Hasan, I.H.; Mahmoud, A.M. Liposomal Resveratrol and/or Carvedilol Attenuate Doxorubicin-Induced Cardiotoxicity by Modulating Inflammation, Oxidative Stress and S100A1 in Rats. Antioxidants 2020, 9, 159. [CrossRef]

15. Hassanein, E.H.M.; Abd El-Ghafar, O.A.M.; Ahmed, M.A.; Sayed, A.M.; Gad-Elrab, W.M.; Ajarem, J.S.; Allam, A.A.; Mahmoud, A.M. Edaravone and Acetovanillone Upregulate Nrf2 and PI3K/Akt/mTOR Signaling and Prevent Cyclophosphamide Cardiotoxicity in Rats. Drug Des. Dev. Ther. 2020, 14, 5275-5288. [CrossRef] [PubMed]

16. Hernandez, P.P.; Undurraga, C.; Gallardo, V.E.; Mackenzie, N.; Allende, M.L.; Reyes, A.E. Sublethal concentrations of waterborne copper induce cellular stress and cell death in zebrafish embryos and larvae. Biol. Res. 2011, 44, 7-15. [CrossRef]

17. Domingo-Relloso, A.; Grau-Perez, M.; Briongos-Figuero, L.; Gomez-Ariza, J.L.; Garcia-Barrera, T.; Dueñas-Laita, A.; Bobb, J.F.; Chaves, F.J.; Kioumourtzoglou, M.-A.; Navas-Acien, A.; et al. The association of urine metals and metal mixtures with cardiovascular incidence in an adult population from Spain: The Hortega Follow-Up Study. Int. J. Epidemiol. 2019, 48, 1839-1849. [CrossRef] [PubMed]

18. Alexanian, I.; Parissis, J.; Farmakis, D.; Athanaselis, S.; Pappas, L.; Gavrielatos, G.; Mihas, C.; Paraskevaidis, I.; Sideris, A.; Kremastinos, D.; et al. Clinical and echocardiographic correlates of serum copper and zinc in acute and chronic heart failure. Clin. Res. Cardiol. 2014, 103, 938-949. [CrossRef] [PubMed]

19. Malamba-Lez, D.; Tshala-Katumbay, D.; Bito, V.; Rigo, J.-M.; Kipenge Kyandabike, R.; Ngoy Yolola, E.; Katchunga, P.; Koba-Bora, B.; Ngoy-Nkulu, D. Concurrent Heavy Metal Exposures and Idiopathic Dilated Cardiomyopathy: A Case-Control Study from the Katanga Mining Area of the Democratic Republic of Congo. Int. J. Environ. Res. Public Health 2021, 18, 4956. [CrossRef] [PubMed]

20. Gunther, M.R.; Hanna, P.M.; Mason, R.P.; Cohen, M.S. Hydroxyl radical formation from cuprous ion and hydrogen peroxide: A spin-trapping study. Arch. Biochem. Biophys. 1995, 316, 515-522. [CrossRef]

21. Sheline, C.T.; Choi, D.W. Cu2+ toxicity inhibition of mitochondrial dehydrogenases in vitro and in vivo. Ann. Neurol. 2004, 55, 645-653. [CrossRef]

22. Rana, S.V. Perspectives in endocrine toxicity of heavy metals-A review. Biol. Trace Elem. Res. 2014, 160, 1-14. [CrossRef] [PubMed]

23. Gaetke, L.M.; Chow-Johnson, H.S.; Chow, C.K. Copper: Toxicological relevance and mechanisms. Arch. Toxicol. 2014, 88, 1929-1938. [CrossRef]

24. Halliwell, B. Oxidative stress and neurodegeneration: Where are we now? J. Neurochem. 2006, 97, 1634-1658. [CrossRef] [PubMed]

25. Kalita, J.; Kumar, V.; Misra, U.K.; Bora, H.K. Memory and Learning Dysfunction Following Copper Toxicity: Biochemical and Immunohistochemical Basis. Mol. Neurobiol. 2018, 55, 3800-3811. [CrossRef] [PubMed]

26. Gera, M.; Sharma, N.; Ghosh, M.; Huynh, D.L.; Lee, S.J.; Min, T.; Kwon, T.; Jeong, D.K. Nanoformulations of curcumin: An emerging paradigm for improved remedial application. Oncotarget 2017, 8, 66680-66698. [CrossRef] [PubMed]

27. Pizzo, P.; Scapin, C.; Vitadello, M.; Florean, C.; Gorza, L. Grp94 acts as a mediator of curcumin-induced antioxidant defence in myogenic cells. J. Cell. Mol. Med. 2010, 14, 970-981. [CrossRef]

28. Saghir, S.A.M.; Alharbi, S.A.; Al-Garadi, M.A.; Al-Gabri, N.; Rady, H.Y.; Olama, N.K.; Abdulghani, M.A.M.; Al Hroob, A.M.; Almaiman, A.A.; Bin-Jumah, M.; et al. Curcumin Prevents Cyclophosphamide-Induced Lung Injury in Rats by Suppressing Oxidative Stress and Apoptosis. Processes 2020, 8, 127. [CrossRef] 
29. Al-Dossari, M.H.; Fadda, L.M.; Attia, H.A.; Hasan, I.H.; Mahmoud, A.M. Curcumin and Selenium Prevent Lipopolysaccharide/ Diclofenac-Induced Liver Injury by Suppressing Inflammation and Oxidative Stress. Biol. Trace Elem. Res. 2020, 196, 173-183. [CrossRef]

30. Farkhondeh, T.; Samarghandian, S. Antidotal Effects of Curcumin Against Agents-Induced Cardiovascular Toxicity. Cardiovasc. Hematol. Disord. Drug Targets 2016, 16, 30-37. [CrossRef]

31. Alhusaini, A.; Fadda, L.; Hasan, I.H.; Zakaria, E.; Alenazi, A.M.; Mahmoud, A.M. Curcumin Ameliorates Lead-Induced Hepatotoxicity by Suppressing Oxidative Stress and Inflammation, and Modulating Akt/GSK-3 $\beta$ Signaling Pathway. Biomolecules 2019, 9, 703. [CrossRef]

32. Mahmoud, A.M.; Ahmed, O.M.; Galaly, S.R. Thymoquinone and curcumin attenuate gentamicin-induced renal oxidative stress, inflammation and apoptosis in rats. EXCLI J. 2014, 13, 98-110. [PubMed]

33. Galaly, S.R.; Ahmed, O.M.; Mahmoud, A.M. Thymoquinone and curcumin prevent gentamicin-induced liver injury by attenuating oxidative stress, inflammation and apoptosis. J. Physiol. Pharmacol. Off. J. Pol. Physiol. Soc. 2014, 65, 823-832.

34. Pop-Moldovan, A.L.; Trofenciuc, N.M.; Dărăbanţiu, D.A.; Precup, C.; Branea, H.; Christodorescu, R.; Puşchiţă, M. Customized laboratory TLR4 and TLR2 detection method from peripheral human blood for early detection of doxorubicin-induced cardiotoxicity. Cancer Gene Ther. 2017, 24, 203-207. [CrossRef]

35. Kenny, E.F.; O’Neill, L.A. Signalling adaptors used by Toll-like receptors: An update. Cytokine 2008, 43, 342-349. [CrossRef] [PubMed]

36. Trofenciuc, N.-M.; Bordejevic, A.D.; Tomescu, M.C.; Petrescu, L.; Crisan, S.; Geavlete, O.; Mischie, A.; Onel, A.F.M.; Sasu, A.; Pop-Moldovan, A.L. Toll-like receptor 4 (TLR4) expression is correlated with T2* iron deposition in response to doxorubicin treatment: Cardiotoxicity risk assessment. Sci. Rep. 2020, 10, 17013. [CrossRef] [PubMed]

37. Flora, G.; Gupta, D.; Tiwari, A. Nanocurcumin: A promising therapeutic advancement over native curcumin. Crit. Rev. Ther. Drug Carr. Syst. 2013, 30, 331-368. [CrossRef]

38. Alhusaini, A.; Hasan, I.H.; Aldowsari, N.; Alsaadan, N. Prophylactic Administration of Nanocurcumin Abates the Incidence of Liver Toxicity Induced by an Overdose of Copper Sulfate: Role of CYP4502E1, NF-kappaB and Bax Expressions. Dose Response 2018, 16, 1559325818816284. [CrossRef]

39. Alhusaini, A.; Fadda, L.; Hassan, I.; Ali, H.M.; Alsaadan, N.; Aldowsari, N.; Aldosari, A.; Alharbi, B. Liposomal Curcumin Attenuates the Incidence of Oxidative Stress, Inflammation, and DNA Damage Induced by Copper Sulfate in Rat Liver. Dose Response 2018, 16, 1559325818790869. [CrossRef] [PubMed]

40. Ohkawa, H.; Ohishi, N.; Yagi, K. Assay for lipid peroxides in animal tissues by thiobarbituric acid reaction. Anal. Biochem. 1979, 95, 351-358. [CrossRef]

41. Ellman, G.L. Tissue sulfhydryl groups. Arch. Biochem. Biophys. 1959, 82, 70-77. [CrossRef]

42. Marklund, S.L. Superoxide dismutase isoenzymes in tissues and plasma from New Zealand black mice, nude mice and normal BALB/c mice. Mutat. Res. 1985, 148, 129-134. [CrossRef]

43. Cohen, G.; Dembiec, D.; Marcus, J. Measurement of catalase activity in tissue extracts. Anal. Biochem. Anal. Biochem. 1970, 34, 30-38. [CrossRef]

44. Hickey, E.J.; Raje, R.R.; Reid, V.E.; Gross, S.M.; Ray, S.D. Diclofenac induced in vivo nephrotoxicity may involve oxidative stress-mediated massive genomic DNA fragmentation and apoptotic cell death. Free Radic. Biol. Med. 2001, 31, 139-152. [CrossRef]

45. Mahmoud, A.M. Hematological alterations in diabetic rats-Role of adipocytokines and effect of citrus flavonoids. EXCLI J. 2013, 12, 647-657. [PubMed]

46. Livak, K.J.; Schmittgen, T.D.J.m. Analysis of relative gene expression data using real-time quantitative PCR and the $2^{-\Delta \Delta C T}$ method. Methods 2001, 25, 402-408. [CrossRef] [PubMed]

47. Jacob, R.; Khan, M. Cardiac Biomarkers: What Is and What Can Be. Indian J. Cardiovasc. Dis. Women WINCARS 2018, 3, $240-244$. [CrossRef] [PubMed]

48. Franchitto, N.; Gandia-Mailly, P.; Georges, B.; Galinier, A.; Telmon, N.; Ducassé, J.L.; Rougé, D. Acute copper sulphate poisoning: A case report and literature review. Resuscitation 2008, 78, 92-96. [CrossRef]

49. Yarmohammadi, F.; Hayes, A.W.; Karimi, G. Protective effects of curcumin on chemical and drug-induced cardiotoxicity: A review. Naunyn-Schmiedeberg's Arch. Pharmacol. 2021, 394, 1341-1353. [CrossRef]

50. Abolaji, A.O.; Fasae, K.D.; Iwezor, C.E.; Aschner, M.; Farombi, E.O. Curcumin attenuates copper-induced oxidative stress and neurotoxicity in Drosophila melanogaster. Toxicol. Rep. 2020, 7, 261-268. [CrossRef]

51. Satta, S.; Mahmoud, A.M.; Wilkinson, F.L.; Yvonne Alexander, M.; White, S.J. The Role of Nrf2 in Cardiovascular Function and Disease. Oxid. Med. Cell. Longev. 2017, 2017, 9237263. [CrossRef] [PubMed]

52. Lu, Y.; Wu, S.; Xiang, B.; Li, L.; Lin, Y. Curcumin Attenuates Oxaliplatin-Induced Liver Injury and Oxidative Stress by Activating the Nrf2 Pathway. Drug Des. Dev. Ther. 2020, 14, 73-85. [CrossRef]

53. Santana-Martínez, R.A.; Silva-Islas, C.A.; Fernández-Orihuela, Y.Y.; Barrera-Oviedo, D.; Pedraza-Chaverri, J.; Hernández-Pando, R.; Maldonado, P.D. The Therapeutic Effect of Curcumin in Quinolinic Acid-Induced Neurotoxicity in Rats is Associated with BDNF, ERK1/2, Nrf2, and Antioxidant Enzymes. Antioxidants 2019, 8, 388. [CrossRef]

54. Yu, L.; Feng, Z. The Role of Toll-Like Receptor Signaling in the Progression of Heart Failure. Mediat. Inflamm. 2018, $2018,9874109$. [CrossRef] 
55. Youn, H.S.; Saitoh, S.I.; Miyake, K.; Hwang, D.H. Inhibition of homodimerization of Toll-like receptor 4 by curcumin. Biochem. Pharmacol. 2006, 72, 62-69. [CrossRef]

56. Gradisar, H.; Keber, M.M.; Pristovsek, P.; Jerala, R. MD-2 as the target of curcumin in the inhibition of response to LPS. J. Leukoc. Biol. 2007, 82, 968-974. [CrossRef]

57. Reddy, P.V.; Rao, K.V.; Norenberg, M.D. The mitochondrial permeability transition, and oxidative and nitrosative stress in the mechanism of copper toxicity in cultured neurons and astrocytes. Lab. Investig. 2008, 88, 816-830. [CrossRef]

58. Roy, D.N.; Mandal, S.; Sen, G.; Biswas, T. Superoxide anion mediated mitochondrial dysfunction leads to hepatocyte apoptosis preferentially in the periportal region during copper toxicity in rats. Chem. Biol. Interact. 2009, 182, 136-147. [CrossRef] [PubMed]

59. Shi, Y.; Chen, J.; Weng, C.; Chen, R.; Zheng, Y.; Chen, Q.; Tang, H. Identification of the protein-protein contact site and interaction mode of human VDAC1 with Bcl-2 family proteins. Biochem. Biophys. Res. Commun. 2003, 305, 989-996. [CrossRef]

60. Redza-Dutordoir, M.; Averill-Bates, D.A. Activation of apoptosis signalling pathways by reactive oxygen species. Biochim. Et Biophys. Acta (BBA)-Mol. Cell Res. 2016, 1863, 2977-2992. [CrossRef] [PubMed]

61. Herrera, B.; Fernández, M.; Alvarez, A.M.; Roncero, C.; Benito, M.; Gil, J.; Fabregat, I. Activation of caspases occurs downstream from radical oxygen species production, $\mathrm{Bcl}-\mathrm{xL}$ down-regulation, and early cytochrome $\mathrm{C}$ release in apoptosis induced by transforming growth factor $\beta$ in rat fetal hepatocytes. Hepatology 2001, 34, 548-556. [CrossRef]

62. Takayama, S.; Sato, T.; Krajewski, S.; Kochel, K.; Irie, S.; Millan, J.A.; Reed, J.C. Cloning and functional analysis of BAG-1: A novel Bcl-2-binding protein with anti-cell death activity. Cell 1995, 80, 279-284. [CrossRef]

63. Yen, F.-L.; Wu, T.-H.; Tzeng, C.-W.; Lin, L.-T.; Lin, C.-C. Curcumin Nanoparticles Improve the Physicochemical Properties of Curcumin and Effectively Enhance Its Antioxidant and Antihepatoma Activities. J. Agric. Food Chem. 2010, 58, 7376-7382. [CrossRef] [PubMed]

64. Nahar, P.P.; Slitt, A.L.; Seeram, N.P. Anti-Inflammatory Effects of Novel Standardized Solid Lipid Curcumin Formulations. J. Med. Food 2014, 18, 786-792. [CrossRef] [PubMed] 